Rodrigues, R. G., Pinheiro, P., Gouveia, A., Brás, R. M., O’Hara, K., Duarte, P., \& Esteves, M. (2017). Segmentation of Portuguese customers' expectations from

\title{
Segmentation of Portuguese customers' expectations from fitness programs
}

\section{Ricardo Gouveia Rodrigues}

NECE - UBI (Research Unit in Business Sciences),

Business and Economics Department, Universidade da Beira Interior

Portugal

Email:rgrodrigues@ubi.pt

\section{Paulo Pinheiro}

NECE - UBI (Research Unit in Business Sciences),

Universidade da Beira Interior

Portugal

Email:pgp@ubi.pt

\section{Ana Gouveia}

Institute of Biophysics and Biomedical Engineering, University of Lisbon, and Faculty of Health Sciences, Universidade da Beira Interior Portugal

Email:anagonveia@fcsaude.ubi.pt

\section{Rui Miguel Marques Brás}

CIDESD (Sports Sciences, Health Sciences and Human Development), Sport Sciences Department, Universidade da Beira Interior, Portugal

Email:rmmb@ubi.pt

\section{Kelly de Lemos Serrano O'Hara}

CIDESD (Sports Sciences, Health Sciences and Human Development), Sport Sciences Department, Universidade da Beira Interior, Portugal

Email:ohara@ubi.pt

\section{Paulo Alexandre de Oliveira Duarte}

NECE - UBI (Research Unit in Business Sciences),

Business and Economics Department, Universidade da Beira Interior Portugal

Email:pduarte@ubi.pt

\section{Maria Dulce Leal Esteves}

Sport Sciences Department, Universidade da Beira Interior Portugal

Email:desteves@ubi.pt 
Abstract. Expectations towards fitness exercises are the major factor in customer satisfaction in the service sector in question. The purpose of this study is to present a segmentation framework for fitness customers, based on their individual expectations. The survey was designed and validated to evaluate individual expectations towards exercises. The study included a randomly recruited sample of 723 subjects (53\% males; 47\% females; $42.1 \pm 19.7$ years). Factor analysis and cluster analysis with Ward's cluster method with squared Euclidean distance were used to analyse the data obtained. Four components were extracted (performance, enjoyment, beauty and health) explaining 68.7\% of the total variance and three distinct segments were found: Exercise Lovers $(n=312)$, Disinterested $(n=161)$ and Beauty Seekers $(n=250)$. All the factors identified have a significant contribution to differentiate the clusters, the first and third clusters being most similar. The segmentation framework obtained based on customer expectations allows better understanding of customers' profiles, thus helping the fitness industry develop services more suitable for each type of customers. A follow-up study was conducted 5 years later and the results concur with the initial study.

Keywords: fitness industry, marketing segmentation, customer's expectations, customer loyalty, designing fitness programs, customer differences, factor analysis, cluster analysis.

JEL Classification: M10, M31, M39

\section{INTRODUCTION}

In 2014, Europe has the estimated total health \& fitness market size worth more than EUR 26.8 billion ( $+4 \%$ considering 2013), with more than $20 \%$ of the total European market of 50.1 million health and fitness club members at the end of 2014 (EuropeActive \& Deloitte, 2015). The International Health, Racquet and Sportsclub Association (IHRSA) states that the health club industry continues to grow, both in the US, in Europe and in China (The IHRS A global report: The State of the Health Club Industry 2016). In fact, leisure sport and fitness industry has maintained a steady growth during the recent years, as the general public becomes more health conscious and the aging population places greater emphasis on staying fit (IBIS World Industry Reports, 2013). This market revenues increased from $\$ 24.2$ billion in 2014 to $\$ 25.8$ billion in 2015, while the membership revenues improved from 54.1 million to 55.3 million over the same time span. The number of clubs grew from 34,460 locations to 36,180 sites in the US alone (The IHRS A global report: The State of the Health Club Industry 2016). However, according to (MacIntosh \& Law, 2015) membership retention in sport and fitness centres is problematic, with an average retention of 40-50\% in a given year. To maintain customers the fitness industry permanently needs to appeal to new (potential) clients.

As the fitness clubs' number increase, their owners have been forced to take a closer look at their revenue streams as well as operation methods in order to re-establish better business strategies (Ferrand, Robinson \& Valette-Florence, 2010; Moreira \& Silva, 2016). The increase of fitness facilities also spurred innovation in the fitness industry by using new and smarter ways of doing business (Athanassopoulou \& Mylonakis, 2009; Campos, Martins, Simões \& Franco, 2017). Gyms’ management began to think of new 
strategies to keep (or improve) their members satisfaction (Ferrand et al., 2010; Zopiatis, Theocharous, Constanti \& Tjiapouras, 2017), since satisfied fitness customers are more likely to continue buying services from the same source (Afthinos, Theodorakis \& Nassis, 2005; Bodet, 2009; Schijns, Caniëls, Le Conté \& Schijns, 2016), but they also consider potential new customers' needs, wants and demands, in other to design fitness products to meet their needs better.

According to (Keenan, 2015), accurate understanding of new (potential) consumer behaviour is the key factor in developing a strategy of membership expansion for fitness clubs. Gonçalves, Meireles \& Carvalho (2016) state that engagement of new customers is related with meeting individual expectations regard exercise. In fact, fulfilled individual expectations are the key to customer satisfaction Jones, Harris, Waller et al., 2005; Robinson, 2006; Resnick, Palmer, Jenkins et al., 2000; Sears \& Stanton, 2001; Zopiatis et al., 2017; Zuzda, Esteves, Pinheiro et al., 2011). To develop a strategy centred on client expansion, clubs' owners must first understand the behaviours of new potential clients, why they buy, what factors influence behaviours, and what expectations clients have about fitness products. Literature suggests that effective marketing segmentation practices can lead to deeper understanding of fitness and leisure sport potential consumers, allowing to redesign fitness offer to better suit new clients' demands, help maintaining business growth (Bodet, 2009; Gonçalves et al., 2016; Liu, Taylor \& Shibli, 2008; Fallon, 2004; Rohm, Milne \& McDonald, 2006). Considering this scenario, the aim of this study is to investigate the general population (actual, former and/or potential fitness clubs' customers) so that to determine the segments that allow the fitness industry develop more suitable offers of activities and services provided.

A market segment is a group of customers who share a similar set of needs and wants (Kotler \& Keller, 2015; Smith, 1956). Market segmentation leads to customisation of operations, thus increasing customer satisfaction (Kotler \& Keller, 2015) and consequently increasing also the profits of organizations. Several variables can be used to identify the market segments and those are usually divided in 4 categories: geographic, demographic, behavioural and psychographic (Kotler \& Keller, 2015; Lesser \& Hughes, 1986). Consumers possess broad and complex motivations for exercise participation (Bodet, 2009; Liu, Taylor \& Shibli, 2008; Pritchard, Nichols \& Graber, 2016). The complexity of understanding consumers' underlying motivations for exercise participation imposes both an opportunity and a challenge for marketers to develop effective and meaningful market segmentation practices (Rohm, Milne \& McDonald, 2006). According to Berger et al. (2002) and Greene \& Greene (2008), it is very important to select the best variables that would allow performing an accurate segmentation which should improve customer service and thus provide higher profits. On the other hand, failure in identifying the true needs of each segments will lead to unsatisfied consumers (Howarton \& Lee, 2010). In this sense, selecting the variables to be used in segmentation is the key factor for obtaining adequate information from customers, that is, information relevant to managerial decisions in the fitness industry.

Literature provides several studies on sport customers' segmentation (e.g.; Rohm et al. 2006; LunaArocas \& Li-Ping Tang 2005; Casper 2007; Ko et al. 2008; Lera-López \& Rapún-Gárate 2011), but little investigation has been made on segmentation of potential new fitness customers. Previous research on fitness customers' segmentation considers gender differences, facilities, personnel attitudes and abilities, cost of participation and items related to programming and scheduling of the services provided (Afthinos, Theodorakis \& Nassis, 2005), age, geographic, cultural and social characteristics, income, motivational factors and perceived barriers to exercise participation (Pritchard, Nichols \& Graber, 2016). Campos et al. (2017) mentions that relevant customer characteristics must be identified to segment the population so that to define the service attributes' contributions to the health club customers' overall satisfaction. Recent investigations concerning fitness participation conside individual expectations as one of the main aspects influencing participation patterns (Afthinos, Theodorakis \& Nassis, 2005; Ferrand, Robinson \& Valette- 
Florence, 2010, Campos et al., 2017). According to Pedragosa \& Correia (2009) and Gonçalves et al. (2016), customers' expectations are considered as an innovative construct in their relationship with consumer satisfaction in the sector of health and fitness clubs. So, customers' expectations as to fitness programmes should be taken in consideration, when studying customers' characteristics. Afthinos et al. (2005) also mention that customers' expectations are considered to be of primary importance while assessing quality and meeting customers' expectations is important in relation to organizations' efforts to retain customers and gain competitive advantage.

Therefore, the purpose of this study is to develop an innovative perspective of marketing segmentation of fitness customers, based on their expectations towards fitness exercise, to achieve a better understanding of customers' characteristics and provide fitness managers with adequate information to properly build strategies to attract and retain clients. The main objective of the paper is thus to establish customer segments and characterize them. This study focused in Portuguese population.

Despite the recognised importance of individual expectations towards exercise, few research projects have been focused on the marketing approach to segmentation of customers based on their expectations and none of them - when it comes to Portuguese population. This investigation presents an innovative segmentation scheme which is an important tool to design fitness programs oriented on potential new customers.

\section{LITERATURE REVIEW}

\subsection{Banks ownership and relationship lending}

Relationship lending, the most common techniques for lending to small firms, is based on the "soft" information which is accessible by keeping a close relationship with the client. Alternatively, there exist transaction-based lending techniques, those are mainly based on the "hard" information about the businesses. For example, financial statements based lending, asset based lending and credit scoring (Petersen $\&$ Rajan, 2002). Researches dealing with the soft information generation and bank lending efficiency argue that the soft information collection and careful examination of the information can increase the lending efficiency of the bank that can positively affect the small business access to credit (D'Aurizio et al., 2015). On the other hand, empirical results show that commercial banks can improve the credit rating model by including the relationship lending qualitative (soft) information of the borrower in the rating process, and that focus only on the hard financial information can be misleading (Dolezal et al., 2015)

\section{METHODOLOGY}

To assess people expectations towards fitness programmes and to identify and characterize the different segments of exercise practitioner's a survey was developed to evaluate individuals' fitness activities objectives; main drop out reasons and providers' individual attribute. The survey was personally applied during first trimester of 2010 the survey by researchers from Universidade da Beira Interior. In order to follow up the results, a second study was conducted, in which a sample was surveyed during the first semester of 2015.

\subsection{Participants}

A sample of 723 subjects randomly selected from all the Portuguese regions were interviewed by the researchers, being $53 \%$ male and $47 \%$ females, ranging from 17 to 85 years of age (mean $=42.1 ; \mathrm{SD}=19.7$ ). 
In the second study (2015) a total of 976 questionnaires were completed, composed of 50,2\% of male respondents, stretching from 15 to 90 years old (mean=42.2; $\mathrm{SD}=19,4)$. The sampling error, given a confidence level of $95 \%$, was 3,64\% for the first study and 3,14\% for the second study.

\subsection{Survey design and procedure}

All measures were assessed using a survey, applied in interview form. The instrument of the survey was a questionnaire developed by a group of 8 people with various backgrounds (sport scientists, marketers, specialists in medical informatics, psychologists, and specialists in knowledge management) with proven expertise in eHealth and in questionnaire design.

Demographic information was collected from all interviewed, namely: age, gender, height and weight (self-reported), marital status, level of education and employment status.

The most determinant individual expectations towards exercise were selected from literature (Andersen et al., 1999; Ryan et al., 1997; Cropley, Ayers \& Nokes, 2003), resulting in a set of 13 individual expectations to be further investigated: (1) muscle definition; (2) cellulite reduction; (3) body beauty improvement; (4) disease prevention; (5) sport performance improvement; (6) Muscular strength increase; (7) agility increase; (8) meet new people; (9) become healthier; (10) have fun; (11) body knowledge improvement, (12) be happier; and (13) decrease stress levels.

The main drop out reasons referred by the literature (Grubbs \& Carter, 2002; Whaley et al., 2006; Gyurcsik, Bray \& Brittain, 2004; Irwin, 2007) were also investigated: (1) distance; (2) price; (3) lack of time; (4) lack of transport options; (5) uninteresting activities; (6) lack of group integration; (7) empathy with the trainer; (8) teaching methods; (9) absence of fun; (10) personal goals not achieved and (11) personal results not achieved.

The main attribute providers cited by King \& Castro (2006) were also examined: (1) price; (2) localization; (3) knowledge about other participants; (4) trainer background; (5) facilities; (6) familiar environment; (7) availability of a physician; (8) innovative activities and (9) diagnosis and control of training.

The survey also contains questions aimed to evaluate the personal objectives when doing fitness activities (Andersen et al., 1999; Cropley, Ayers \& Nokes, 2003; Grubbs \& Carter, 2002; Whaley et al., 2006), such as (1) losing weight; (2) disease prevention; (3) increase mobility; (4) socializing; (5) spending time; (6) learning healthy lifestyles; (7) disease recovery; (8) having fun; (9) feeling better with the body. The variables were assessed using closed questions with multiple choice options using a five-point Likert scale (5 meaning "strongly agree" and 1 meaning "strongly disagree").

To ensure content and face validity, all items were reviewed by an expert panel of professors and researchers not involved in the study. The board consisted of 2 sport scientists (with research experience), 1 expert researcher on market studies survey development and 1 expert researcher on knowledge management. To guarantee clarity and completion time the survey was reviewed by 2 experts and 15 nonstudy participants. Surveys were administered by 10 independent research post-graduate students to ensure confidentiality. All interviews were conducted and completed face to face in public places.

Before the field work an evaluation of instrument and procedures was conducted. The survey was sometimes considered long and researcher have to motivate participants to answer to all questions. No considerable difficulties in the implementation of the survey were found. Special care was taken with coding individual survey result. This study was conducted with the Ethics Committee of the University of Beira Interior approval. 


\subsection{Data analysis}

Data was analysed with SPSS statistical software (IBM Corp. Released, 2010). An exploratory factor analysis using the correlation matrix was used to analyse the variables concerning expectations towards fitness participation. A cluster analysis, using Ward's cluster method (Ward, JH, 1963) with squared Euclidean distance, was performed based on importance given to the expectation factors. A non-parametric Kruskal-Wallis one-way ANOVA (Kruskal \& Wallis, 1952) with pairwise multiple comparisons was performed to test for group differences.

\section{EMPIRICAL RESULTS}

\subsection{Data screening}

The data was screened for univariate outliers but no outliers were identified. To perform an exploratory factor analysis with 13 variables, the minimum amount of data was checked. The final sample size of 723 (using listwise deletion) resulted in over 55 cases per variable.

\subsection{Factor analysis}

The relational structure of the 13 variables concerning expectations of respondents regarding health sport programmes was assessed with Exploratory Factor Analysis using the correlation matrix. The factorability of the 13 items was examined with three criteria for the factorability of a correlation. Firstly, all the 13 items correlated at least .3 with at least one other item, suggesting reasonable factorability. Secondly, the Kaiser-Meyer-Olkin measure of sampling adequacy was .85, above the recommended value of .5 (Hair et al., 2010), and Bartlett's test of sphericity was significant $\left(\chi^{2}(78)=3719.72, \mathrm{p}<.05\right)$. The diagonals of the anti-image correlation matrix were all over .5, except for one item (which was excluded from the analysis) supporting the inclusion of every other items in the factor analysis. Finally, the communalities were all above .3 (see Table 1), further confirming that each item shared some common variance with other items. Given these overall indicators, factor analysis was conducted with 12 of the 13 original items.

Principle components analysis was used to identify and compute composite scores for the factors underlying the items. The initial solution showed three factors with eigenvalues above 1 . The first factor explained $38.3 \%$ of the variance, the second factor $12.9 \%$ of the variance, and a third factor $10.2 \%$ of the variance. The fourth factor had an eigenvalue .95 explaining $7.4 \%$ of the variance. Three, four, and five factor solutions were examined, using varimax rotation (Kaiser, 1958) of the factor loading matrix. The four-factor solution, which explained $68.7 \%$ of the variance, was preferred because of difficulty of interpreting other solutions. In the final solution, presented in Table 1, all the items had loadings above .5.

According to the items that loaded in the four factors, they were named performance, enjoyment, beauty and health. representing different dimensions of the importance given to fitness activity by respondents.

All the factors present acceptable internal consistency, with all Cronbach's alphas (Cronbach, 1951) above .7, as shown on Table 1. No increases in alpha for any of the scales could have been achieved by eliminating any items. 
Table 1

Factor loadings and communalities

\begin{tabular}{|c|c|c|c|c|c|}
\hline Mean & Performance & Enjoyment & Beauty & Health & $\begin{array}{c}\text { Commu- } \\
\text { nalities }\end{array}$ \\
\hline Become stronger & .83 & & & & .66 \\
\hline Perform better in sports & .77 & & & & .84 \\
\hline Have more defined muscles & .70 & & & & .79 \\
\hline Become more agile & .65 & & & & .77 \\
\hline Meet new friends & & .80 & & & .69 \\
\hline Have Fun & & .80 & & & .76 \\
\hline Be happier & & .75 & & & .66 \\
\hline Have a better knowledge of my own body & & .56 & & & .67 \\
\hline Reduce cellulitis & & & .90 & & .73 \\
\hline Have a nicer body & & & .79 & & .73 \\
\hline Have less diseases, now and in the future & & & & .84 & .58 \\
\hline Be healthier & & & & .75 & .68 \\
\hline Explained variance $(\%)$ & 19.3 & 18.8 & 15.5 & 15.1 & \\
\hline Cronbach's Alpha & .79 & .79 & .76 & .73 & - \\
\hline
\end{tabular}

Composite scores were created for each of the four factors, based on the mean of the items which had their primary loadings on each factor. Higher scores indicated greater importance of the dimension. As

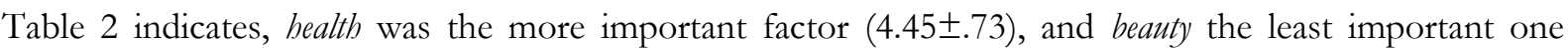
(2.88 \pm 1.31$)$. It was also noticeable that beauty showed the biggest standard deviation, pointing to large differences in the appreciation by respondents of the importance of beauty aspects in sport activity.

Table 2

Descriptive statistics of the factors $(n=726)$

\begin{tabular}{lccccc}
\hline \multicolumn{1}{c}{ Dimension } & $\begin{array}{c}\text { Number of } \\
\text { items }\end{array}$ & Mean & $\begin{array}{c}\text { Std. } \\
\text { Deviation }\end{array}$ & Skewness & Kurtosis \\
\hline Performance & 4 & 3.38 & .97 & -.39 & -.36 \\
Enjoyment & 4 & 3.63 & .91 & -.61 & .15 \\
Beauty & 2 & 2.88 & 1.31 & .13 & -1.11 \\
Health & 2 & 4.45 & .73 & -1.77 & 4.16 \\
\hline
\end{tabular}

\subsection{Customer segments}

Composite scores were the used as clustering variables in a hierarchical cluster analysis, using squared Euclidean distance as similarity measure with Ward's method (Ward, JH, 1963). In cluster analysis there are no standard objective selection procedures (Bock, 1985; Hair et al., 2010; Hartigan, 1985), so ad-hoc procedures are normally adopted to determine the number of clusters. Based on the agglomeration distances on the dendrogram, three clusters were identified. Clusters' centroids are shown in Table 3 and graphed on Figure 1. 
Clusters' centroids and F statistics for each cluster

\begin{tabular}{lcccc}
\hline & Performance & Enjoyment & Beauty & Health \\
\hline Group I $(n=312)$ & 3.49 & 3.80 & 2.29 & 4.81 \\
Group II $(n=161)$ & 2.82 & 2.85 & 2.00 & 3.49 \\
Group III $(n=250)$ & 3.61 & 3.91 & 4.20 & 4.63 \\
\hline F $\quad 38.65^{*}$ & $94.96^{*}$ & $424.19^{*}$ & $392.50^{*}$ \\
\hline${ }^{*} \mathrm{p}<.001$ & & &
\end{tabular}

The F statistic indicated that all the dimensions differentiated the clusters. Beanty $(\mathrm{F}=424.19)$ is the dimension that differentiates more the clusters, followed by Health $(\mathrm{F}=392.50)$, Enjoyment $(\mathrm{F}=94.96)$ and Performance $(\mathrm{F}=38.65)$.

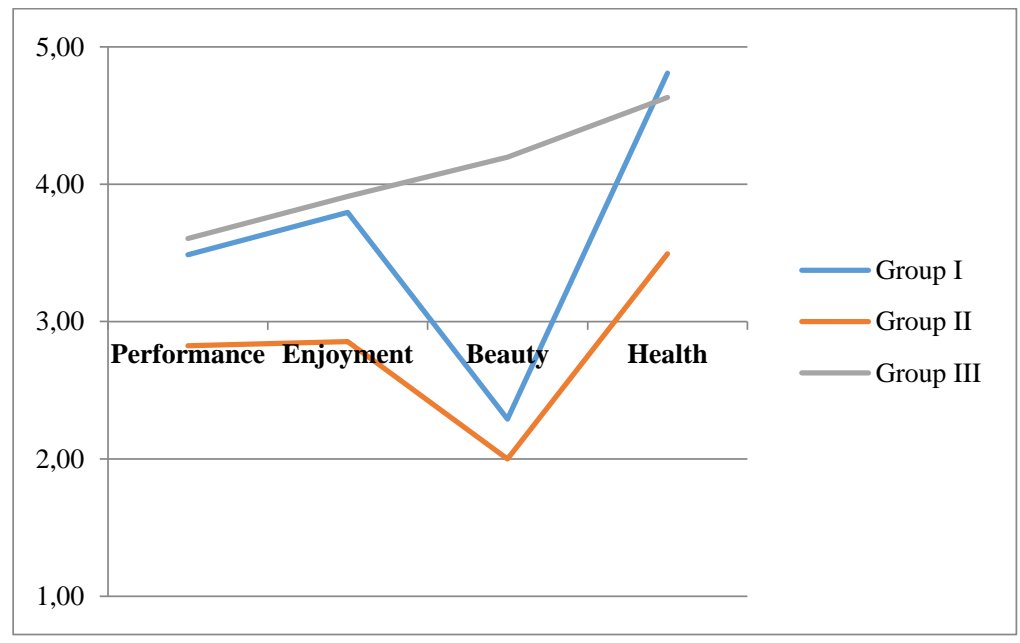

Figure 1. Clusters' centroids

Only cluster III showed a positive (above the neutral value in the scale 3) importance to beauty, and had the highest values for all the dimensions except for Health. Cluster II valued negatively all the dimensions but health, which is the most valued dimension across the three clusters. Cluster I exhibited a similar pattern of importance as of cluster II, but with positive values except for beauty, and had also the highest importance to a dimension, bealth, with a mean value of 4.81 .

Table 4

Groups’ descriptives

\begin{tabular}{|c|c|c|c|c|c|c|}
\hline & Age & $\mathrm{M} \pm \mathrm{SD}$ & \% Women & $\begin{array}{c}\% \text { Basic } \\
\text { Education }\end{array}$ & $\begin{array}{l}\text { \% Secondary } \\
\text { Education }\end{array}$ & $\begin{array}{l}\% \text { College } \\
\text { Education }\end{array}$ \\
\hline Group I $(n=312)$ & \multicolumn{2}{|c|}{$44.8 \pm 20.5$} & $37.5 \%$ & $47.4 \%$ & $23.9 \%$ & $28.7 \%$ \\
\hline Group II (n=161) & \multicolumn{2}{|c|}{$44.3 \pm 21.8$} & $28.0 \%$ & $37.3 \%$ & $31.7 \%$ & $31.1 \%$ \\
\hline Group III $(n=250)$ & \multicolumn{2}{|c|}{$37 \pm 15.8$} & $72.0 \%$ & $32.0 \%$ & $34.0 \%$ & $34.0 \%$ \\
\hline
\end{tabular}

Percentages were computed based on group sizes. 
Table 4 presents a short description of the groups. Group I is very like Group II in what concerns to age, is composed mainly by males, and by respondents with only basic education. Group II is predominantly male, and Group III is predominantly female.

With the purpose of further knowing the peculiarities of each group a non-parametric Kruskal-Wallis one-way ANOVA (Kruskal \& Wallis, 1952) with pairwise multiple comparisons was performed on three groups of variables (Table 5). The parametric ANOVA could not be used, once the normality assumption was violated for the three groups according to the Kolmogorov-Smirnov test (Massey Jr, 1951) with Lilliefors correction (Lilliefors, 1967).

Table 5

Kruskal-Wallis ANOVA and group means

\begin{tabular}{|c|c|c|c|c|c|c|c|c|}
\hline & $\begin{array}{c}\text { Chi- } \\
\text { Square } \\
(\mathrm{df}=2)\end{array}$ & $\begin{array}{c}\text { Average } \\
\text { Rank } \\
\text { difference } \\
\text { I - II }\end{array}$ & $\begin{array}{c}\text { Average } \\
\text { Rank } \\
\text { difference } \\
\text { I - III }\end{array}$ & $\begin{array}{c}\text { Average } \\
\text { Rank } \\
\text { difference } \\
\text { II - III }\end{array}$ & $\begin{array}{c}\text { Group } \\
\text { I } \\
\text { Mean }\end{array}$ & $\begin{array}{l}\text { Group } \\
\text { II } \\
\text { Mean }\end{array}$ & $\begin{array}{l}\text { Group } \\
\text { III } \\
\text { Mean }\end{array}$ & $\begin{array}{c}\text { Sample } \\
\text { Mean }\end{array}$ \\
\hline \multicolumn{9}{|l|}{ Objectives when doing health sport } \\
\hline Losing weight & $96.97^{*}$ & 41.91 & $-139.03^{*}$ & $-180.94^{*}$ & 3.03 & 2.73 & 3.94 & 3.29 \\
\hline Disease prevention & $119.13^{*}$ & $-185.24^{*}$ & -23.46 & $161.79^{*}$ & 4.67 & 3.8 & 4.61 & 4.46 \\
\hline Increase mobility & $73.53^{*}$ & $-160.16^{*}$ & $-52.02^{*}$ & $-108.14^{*}$ & 4.47 & 3.73 & 4.26 & 4.24 \\
\hline Socializing & $70.15^{*}$ & $-160.30^{*}$ & -37.69 & $-123.62^{*}$ & 4.02 & 3.16 & 3.83 & 3.78 \\
\hline Spending time & $39.60^{*}$ & $-117.77^{*}$ & -8.47 & $-109.29^{*}$ & 3.38 & 2.66 & 3.32 & 3.22 \\
\hline Learning healthy lifestyles & $93.94^{*}$ & $-163.24^{*}$ & -14.58 & $-177.82^{*}$ & 4.21 & 3.39 & 4.28 & 4.06 \\
\hline Disease recovery & $46.86^{*}$ & $-105.45^{*}$ & -27.25 & $-132.69^{*}$ & 4.00 & 3.4 & 4.16 & 3.94 \\
\hline Having fun & $40.33^{*}$ & $-120.97^{*}$ & -23.47 & $-97.50^{*}$ & 4.04 & 3.33 & 3.94 & 3.85 \\
\hline Feeling better with the body & $75.80^{*}$ & $-130.95^{*}$ & -38.13 & $-169.08^{*}$ & 4.11 & 3.35 & 4.35 & 4.03 \\
\hline \multicolumn{9}{|l|}{ Reasons to drop out } \\
\hline Distance & $22.38^{*}$ & $-49.64^{* *}$ & -36.47 & $-86.10^{*}$ & 2.79 & 2.37 & 3.11 & 2.79 \\
\hline Price & $17.15^{*}$ & $50.02^{* *}$ & -24.70 & $-74.71^{*}$ & 3.23 & 2.77 & 3.43 & 3.18 \\
\hline Lack of time & $18.30^{*}$ & $-43.40^{* *}$ & -33.66 & $-77.06^{*}$ & 3.48 & 3.15 & 3.84 & 3.52 \\
\hline Lack of transpor & $11.33^{*}$ & -12.95 & $-42.58^{* *}$ & $-55.53^{*}$ & 2.46 & 2.32 & 2.81 & 2.53 \\
\hline Uninteresting activities & $19.60^{*}$ & -28.96 & $-48.85^{*}$ & $-77.81^{*}$ & 2.68 & 2.46 & 3.06 & 2.75 \\
\hline Identification with group & $8.04^{* *}$ & -12.59 & -34.56 & -47.15 & 2.31 & 2.17 & 2.55 & 2.35 \\
\hline Empathy with the trainer & $17.26^{*}$ & -17.47 & $-51.45^{*}$ & $-68.92^{*}$ & 2.36 & 2.21 & 2.78 & 2.46 \\
\hline Teaching methods & $16.43^{*}$ & -22.62 & $-46.85^{*}$ & $-69.47^{*}$ & 2.46 & 2.28 & 2.84 & 2.54 \\
\hline Absence of fun & 5.73 & - & - & - & 2.78 & 2.52 & 2.89 & 2.75 \\
\hline Personal goals $\mathrm{n}$ & $19.95^{*}$ & -57.6 & -21.30 & $-78.92^{*}$ & 3.00 & 2.50 & 3.18 & 2.93 \\
\hline Personal results not achieved & $19.66^{*}$ & $-42.38^{* *}$ & -37.69 & $-80.07^{*}$ & 2.93 & 2.57 & 3.25 & 2.94 \\
\hline \multicolumn{9}{|l|}{ Importance of providers' Attributes } \\
\hline Price & $32.80^{*}$ & $-87.28^{*}$ & -25.04 & $-112.32^{*}$ & 3.84 & 3.25 & 3.98 & 3.74 \\
\hline Localization & $36.74^{*}$ & $-104.54^{*}$ & -8.24 & $-112.77^{*}$ & 3.83 & 3.11 & 3.83 & 3.66 \\
\hline Knowledge about other participants & $27.37^{*}$ & $-101.75^{*}$ & -24.76 & $-77.00^{*}$ & 3.18 & 2.53 & 3.03 & 2.99 \\
\hline Trainer background & $32.23^{*}$ & $-108.47^{*}$ & -27.42 & $-81.04^{*}$ & 4.05 & 3.44 & 3.95 & 3.90 \\
\hline Facilities & $57.78^{*}$ & $-125.98^{*}$ & -2.02 & $-123.97^{*}$ & 4.48 & 3.86 & 4.50 & 4.35 \\
\hline Familiar environment & $44.59^{*}$ & $-115.82^{*}$ & -8.11 & $-123.93^{*}$ & 3.53 & 2.84 & 3.60 & 3.41 \\
\hline Availability of a physician & $30.64^{*}$ & $-80.80^{*}$ & -28.52 & $-109.32^{*}$ & 3.91 & 3.48 & 4.08 & 3.88 \\
\hline Innovative activities & $53.74^{*}$ & $-107.15^{*}$ & -37.66 & $-144.81^{*}$ & 3.90 & 3.29 & 4.13 & 3.85 \\
\hline Diagnosis and control of training & $51.42^{*}$ & $-128.03^{*}$ & -15.66 & $-112.38^{*}$ & 4.30 & 3.65 & 4.28 & 4.16 \\
\hline
\end{tabular}

$$
* \mathrm{p}<.01 \quad * * \mathrm{p}<.05
$$




\subsection{Follow-up study}

Composite scores for the four factors, Performance, Enjoyment, Beauty, and Health, were computed for the 976 observations in the 2015 study. Respondents were grouped using composite scores as clustering variables in a hierarchical cluster analysis, using squared Euclidean distance as similarity measure with Ward's method (Ward, JH, 1963), as done in study one, resulting in three groups.
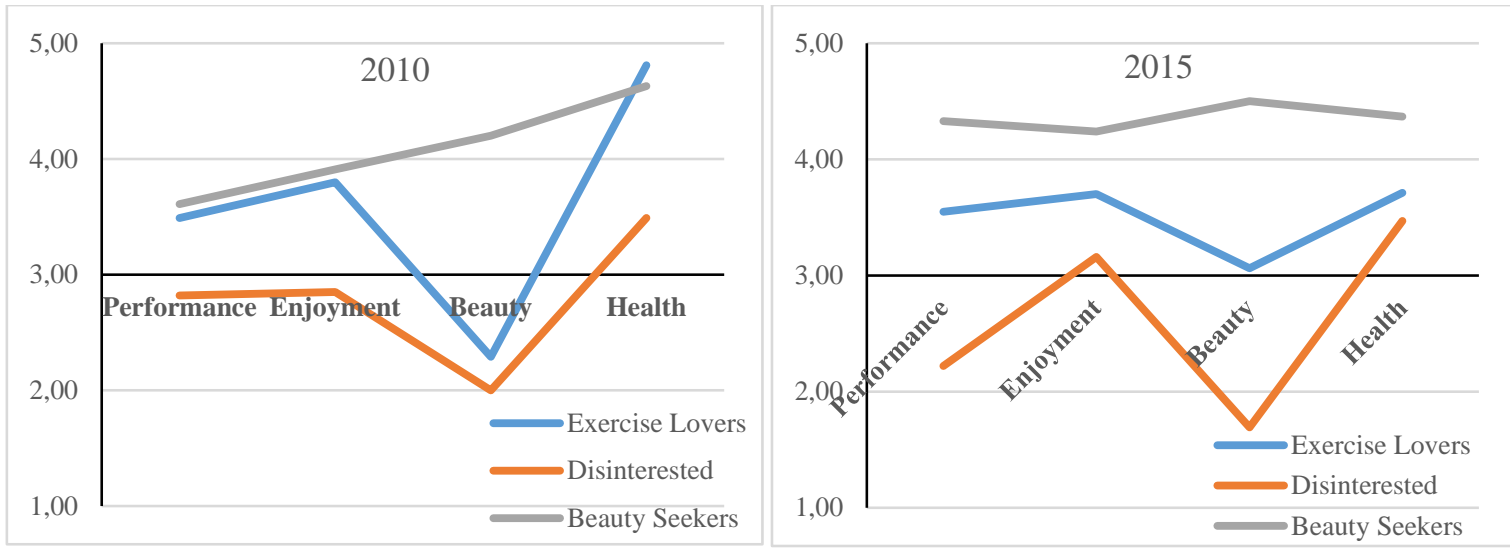

Figure 2. Clusters' centroids - Study 2

Figure 2 shows that Group III slightly increases the importance given to Performance, Group I presents a positive (above 3) value for Beauty, and Group II increases a bit the importance of Enjoyment. Nevertheless, the three groups present similar configurations of the three factors in both studies.

\section{DISCUSSION}

This study aimed to segment general population, based on their expectations towards fitness programmes. Analysis revealed 4 factors (performance, enjoyment, beanty and health) that were underneath the respondents' expectations towards exercise. Through these factors a cluster analysis was performed, from which 3 segments emerged.

The first segment - Exercise Lovers - is composed of individuals of all ages (44.8 \pm 20.5 years old), that has a low-level education (47.4\% with basic education) and consists mainly of men (62.5\%). This group, like the other two, considers that exercise is an important factor for health. However, Table 3 also shows positive values on Clusters' centroids for enjoyment (3.80) and performance (3.29). Moreover, the analysis of the individual objectives when they made exercise (Table 5), show that "Learning healthy lifestyles" (4.21), "Feeling better with the body" (4.11) and "Having fun" (4.04) are the most indicated objectives of these individuals. These results indicate that this cluster - Exercise Lovers - enjoys physical activity and fitness and have their expectations associated with exercise outcomes. These individuals seem to seek activities that enhance their physical performance, find fitness as an activity that brings satisfaction per se. For this segment, data analysis suggests that companies should develop fitness programs that enhance physical performance including a recreational component to increase satisfaction and compliance. One must not forget that these programs should also be focused on a perspective that will contribute to a healthy life, as considered by in particular programs that promote disease prevention (4.67) and mobility increase (4.47). This last parameter was significantly different $(p<.01)$ when compared to the other two segments (Table 5$)$. This fact can be explained by the positive association between mobility and health. 
The second segment - Disinterested - is composed of individuals of all ages ( $44.3 \pm 21.8$ years old) predominantly male $(72 \%)$ with a level of education higher than Exercise Lovers. In general, this segment shows little interest neither in physical activity nor in fitness programmes. Even considering the importance of exercise for health benefits, they present the lowest cluster centroid value (3.49) for this factor, compared with the other groups (Table 3). They valued negatively all other dimensions, indicating that these individuals do not attach importance to the relationship between exercise and performance, enjoyment and beauty. This segment has the lowest values in all factors showing a gap between physical exercise and the factors presented (Table 5). The presence of a segment that has no interest in the practice of exercise is consistent with the literature (Borodulin et al., 2016). According to TNS Opinion \& Social, 2014, 59\% of Europeans over 15 years present high levels of physical inactivity. The lack of interest shown by members of this group regarding physical activity may be an indicator to the managers of fitness centres that strategically they should not develop specific programs to them, since it would be very difficult to change their inactivity behaviour. Wahlich et al., 2017, suggest the use of technologic devices, such pedometer or caloric expenditure measurements as strategies to increase this segment engagement on fitness club.

The third segment - Beauty Seekers - is mainly composed of young and mature ( $37 \pm 15.8$ years old) women $(72 \%)$, with the highest level of education. Individuals in this segment appreciate positively all the factors, being the only one that gives a strong importance to the factor beauty (4.20). In fact, this is one of the main differences appear between first and third groups. While the first segment seeks an improvement on performance, health and enjoyment, individuals of this segment seek beauty as an important factor for exercise. Moreover, the Beauty Seekers denote a higher interest on exercise effects on body appearance, with more specific objectives, when compared to Exercise Lovers who sought to pursue objectives which may arise in a wider level. For example, when comparing the three segments with respect to the objectives (Table 5) the item "Feeling better with the body" is the most valued by third segment (4.35). This result is similar with findings reported by Salci \& Ginis (2017). On the other hand, this segment was most interested in programs that enable weight loss, parameter significantly different when compared to the other two segments (Table 5). In fact, lose weight is one of the most expectation towards exercise referred on literature (Batsis, 2017; Gonçalves et al., 2016; Robinson et al., 2017). This contributes to evidence of the importance of the "looking good", according to beauty standards of modern societies that emphasise body thinness (Robinson, Prichard, Nikolaidis, Drummond, Drummond \& Tiedeman, 2017). The fitness programs for this segment should be designed to improve the perception of beauty and the body beauty and mobility. As Beanty Seekers, this segment has a potential to be a customer of other fitness facilities beside exercise, such massages, sauna, beauty treatments, hair dresser; beauty accessories, etc. These services should be considered by managers of fitness centres. The three segments defined are in line with the theoretical framework proposed by Seippel (2006).

\section{CONCLUSION}

Customers' expectations are crucial to the adoption of fitness programs and services. Designing better and more appealing offers are crucial to encourage individuals to enrol fitness clubs. Since expectation is a major factor to customer satisfaction, the current study presents a marketing segmentation for fitness customers, based on their expectations towards fitness exercise, using a large population to assist fitness clubs to customize the offer. This study is also a contribution to marketing research, since no previous attempt to develop a marketing segmentation in the fitness market using expectations as the central variable is reported in the literature. 
Based on the gap identified in the literature, this study establishes segments based on customers' expectations that allow Leisure sports \& fitness industry to develop more adequate activities and services, to improve customers' satisfaction. The results from the 2010 and 2015 studies consistently revealed the existence of three distinct groups of fitness clients: (1) Exercise Lovers, (2) Disinterested and (3) Beauty Seekers. Exercise lovers are mainly concerned with the dimension of performance, enjoyment and health. Is interesting to note that the perception that this segment has of the beauty dimensions clearly changed from 2010 to 2015. Based on what was found, fitness clubs should design more balanced programs to attract this segment since they have expectation on all dimensions. Health benefits seem to be a concern common to all segments and firms should emphasise this motivational factor in the design of fitness proposals and communication, since it influences all groups. Between the 2010 and 2015 is noteworthy that the several segments present mixed evolution. Beauty seekers and disinterested show an increase in the interest on performance, but at the same time exercise lovers present a significant decrease in the beauty and health dimensions health dimension, which is curious and should be closely followed by fitness operators to tailor its offer to address these changes. The beauty seeker seems to be the segment with the more consistent behaviour, thus become an interested group for loyalty programs. Individuals in the disinterested segment have no defined or specific interest, therefore fitness firms must diversify their offer to attract the type of customer that predictably will regularly jump from one type of exercise to another depending upon their interests and the opportunities available at that time. Based on the results from the two studies, fitness managers should consider attract new customers and retain existing ones among exercise lovers and beauty seekers, and develop a steady flow of innovative offers to generate interest among the individuals in the disinterested segment.

Regarding the objectives for fitness, reasons to drop out and importance of provider's attributes (Table 5), segments (1) and (3) are very similar and statically different from segment (2) in almost all parameters analysed. The main differences found regard weight loss, more valuated by the Beauty Seekers and body mobility more valuated by Exercise Lovers.

The findings obtained from this study will help to optimize management decisions based on customers' satisfaction, avoiding drop outs and recession effects, according to IHRSA (2016) recommendations fitness industry should respond to consumers' need for new ideas or change by adapting programs to costumer's preferences and expectations.

\subsection{Contributions to scholarship}

Implications of this study for marketing research are that, given the complex mind-set of fitness participants where rational and emotional, as well as extrinsic and intrinsic expectations, may determine exercise participation, segment customers based on their expectations is an innovative approach. This segmentation revealed three segments witch analysis allow fitness industry to achieve a better understand on customers, promoting a better adaptation of its offer to customers' expectations.

According to Berger et al. (2002) and Greene \& Greene (2008), the variable selection for marketing segmentation determines the usefulness of segments obtained, from the manager point of view. Since expectation is a major factor to customer satisfaction, we present a marketing segmentation for fitness customers, based on their expectations towards fitness exercise, using a large population. This is a contribution to fitness management, since a marketing segmentation concerning expectations as variable has not yet been reported in literature. 


\subsection{Applied implications}

The findings obtained from this study will help to optimize management decisions based on customers' satisfaction, avoiding drop outs and recession effects.

Specifically, the segmentation presented recommends to fitness facilities managers to reinforce the enjoyment on activities; propose fitness activities that specifically promote weight loss and body definition; should not consider an unmotivated segment, when thinking in attract new customers and should innovate the existing offer by introducing parallel services that promote customers' beauty.

\subsection{Limitations and future research directions}

Major limitation of present work, besides common limitations to marketing segmentation research (such as possibility of presence of "universals" in the questionnaire - statements that everyone agrees with, or everyone disagrees with, that impair multivariate analyses, presence of attitudinal statements in the questionnaire will not show up in the final segments; creating too many or too little segments, (Wedel \& Kamakura, 2012) is the fact that the segments found are too generic, needing a deeper analysis.

Another limitation is related with the indifference about exercise found on the "Disinterested" segment, which is not quite understood, since these individuals don't show any motivation to drop out the exercise practice and consider that exercise is important to health. Finally, it should point out the difficulty in comparing our results with other in literature, since this kind of segmentation in fitness industry was not found.

Future research examining segmentation models to fitness customers might explore questions directly related to age, since this investigation found groups with considerable age differences.

\section{ACKNOWLEDGEMENT}

Research funded by FCT - Portuguese Foundation for the Development of Science and Technology, project UID/GES/04630/2013.

\section{REFERENCES}

Afthinos, Y., Theodorakis, N.D. \& Nassis, P. (2005) Customers' expectations of service in Greek fitness centers: Gender, age, type of sport center, and motivation differences. Managing Service Quality: An International Journal, 15(3), 245-258. doi:10.1108/09604520510597809.

Andersen, R.E., Wadden, T.A., Bartlett, S.J., Zemel, B., et al. (1999) Effects of lifestyle activity vs structured aerobic exercise in obese women: A randomized trial. JAMA, 281(4), 335-340. Retrieved from http://dx.doi.org/101001/pubs.JAMA-ISSN-0098-7484-281-4-joc80705.

Athanassopoulou, P. \& Mylonakis, J. (2009) The quality of the relationships between fitness centres and their customers. International Journal of Sport Management and Marketing, 5(3), 355. doi:10.1504/IJSMM.2009.023243.

Batsis, J. A., Gill, L. E., Masutani, R. K., Adachi-Mejia, A. M., Blunt, H. B., Bagley, P. J., ... \& Bartels, S. J. (2017). Weight loss interventions in older adults with obesity: a systematic review of randomized controlled trials since 2005. Journal of the American Geriatrics Society, 65(2), 257-268. doi:10.1111/jgs.14514.

Berger, P.D., Bolton, R.N., Bowman, D., Briggs, E., et al. (2002) Marketing Actions and the Value of Customer Assets: A Framework for Customer Asset Management. Journal of Service Research, 5(1), 39-54. doi:10.1177/1094670502005001005.

Bock, H. H. (1985) On some significance tests in cluster analysis. Journal of Classification, 2(1), 77-108. doi:10.1007/BF01908065 [Accessed: 6 October 2011].

Bodet, G. (2009) An investigation of the influence of consumer value on service elements' contributions to satisfaction. Journal of Targeting, Measurement and Analysis for Marketing, 17(3), 205-228. doi:10.1057/jt.2009.15. 
Borodulin, K., Sipilä, N., Rahkonen, O., Leino-Arjas, P., Kestilä, L., Jousilahti, P., \& Prättälä, R. (2016). Sociodemographic and behavioral variation in barriers to leisure-time physical activity. Scandinavian Journal of Social Medicine, 44(1), 62-69. doi:10.1177/1403494815604080.

Campos, F., Martins, F., Simões, V., \& Franco, S. (2017). Fitness participants perceived quality by age and practiced activity. Journal of Physical Education and Sport, 17(2), 698. doi:10.7752/jpes.2017.02105.

Casper, J. (2007) Sport Commitment, Participation Frequency and Purchase Intention Segmentation based on Age, Gender, Income and Skill Level with US Tennis Participants. European Sport Management Quarterly, 7(3), 269_ 282. doi:10.1080/16184740701511110.

Cronbach, L.J. (1951) Coefficient alpha and the internal structure of tests. Psychometrika, 16(3), 297334doi:10.1007/BF02310555.

Cropley, M., Ayers, S. \& Nokes, L. (2003) People don't exercise because they can't think of reasons to exercise: an examination of causal reasoning within the Transtheoretical Model. Psychology, Health \& Medicine, 8(4), 409-414. doi:10.1080/13548500310001604540.

EuropeActive \& Deloitte (2015). European Health \& Fitness Market Report. Retrieved from: www.europeactive.eu/blog/europeactive-and-deloitte-publish-new-official-european-health-fitness-marketreport.

Fallon, J. (2004). New thinking on health and fitness. Journal of Retail \& Leisure Property, 3(4), 307-313. Retrieved from: doi:10.1057/palgrave.rlp.5090185.

Ferrand, A., Robinson, L. \& Valette-Florence, P. (2010). The intention-to-repurchase paradox: $A$ case of the health and fitness industry, 24(1), 83-105.

Gonçalves, C., Meireles, P., \& Carvalho, M. J. (2016). Consumer behaviour in Fitness Club: study of the weekly frequency of use, expectations, satisfaction and retention. The Open Sports Sciences Journal, 9(1). doi:10.2174/1875399X01609010062.

Greene, H. \& Greene, S. (2008). Enhancing segmentation systems. Journal of Targeting, Measurement and Analysis for Marketing, 16(4), 298-311. doi:10.1057/jt.2008.22.

Grubbs, L. \& Carter, J. (2002) The Relationship of Perceived Benefits and Barriers to Reported Exercise Behaviors in College Undergraduates. Family \& Community Health, 25(2), 76-84. doi:10.1097/00003727-200207000-00009.

Gyurcsik, N.C., Bray, S.R. \& Brittain, D.R. (2004). Coping With Barriers to Vigorous Physical Activity During Transition to University. Family \& Community Health, 27(2), 130-142. doi:10.1097/00003727-200404000-00006.

Hair, J.F.J., Black, W.C., Babin, B.J. \& Anderson, R.E. (2010). Multivariate Data Analysis. 7th edition. Prentice Hall.

Hartigan, J.A. (1985). Statistical theory in clustering. Journal of Classification, 2(1), 63-76. doi:10.1007/BF01908064.

Howarton, R. \& Lee, B. (2010). Market analysis of fit preferences of female boomers. Journal of Fashion Marketing and Management: An International Journal, 14(2), 219-229. doi:10.1108/13612021011046075.

IBIS World Industry Reports (2013). Gym, Health \& Fitness Clubs in the US: Market Research Report. Retrieved from www.ibisworld.com/industry/default.aspx?indid $=1655$.

IBM Corp. Released (2010) IBM SPSS Statistics for Windows.

IHRSA (2016). The IHRS A global report: The State of the Health Club Industry. Retrieved from www.ihrsa.org/ihrsa-globalreport.

Irwin, J.D. (2007). The Prevalence of Physical Activity Maintenance in a Sample of University Students: A Longitudinal Study. Journal of American College Health, 56(1), 37-42. doi:10.3200/JACH.56.1.37-42.

Jones, F., Harris, P., Waller, H. \& Coggins, A. (2005). Adherence to an exercise prescription scheme: The role of expectations, self-efficacy, stage of change and psychological well-being. British Journal of Health Psychology, 10(3), 359-378. doi:10.1348/135910704X24798.

Kaiser, H.F. (1958). The varimax criterion for analytic rotation in factor analysis. Psychometrika, 23(3), $187-200$. doi:10.1007/BF02289233.

Keenan, R. (2015). A Systematic Analysis of Personal Training Client Retention Rates for Sport and Health, Crystal Park. Unpublished Master Thesis. George Mason University.

Ko, Y.J., Claussen, C.L. \& Park, H. (2008). Action sports participation: consumer motivation. International Journal of Sports Marketing and Sponsorship, 9(2), 111-124. Retrieved from https://www.scopus.com/inward/record.uri?eid=2-s2.070349216843\&partnerID=40\&md5=aa78effb16e3df56c014178457e2435e.

Kotler, P. \& Keller, K.L. (2015). Marketing Management. 15th edition. Pearson. 
Kruskal, W.H. \& Wallis, W.A. (1952). Use of ranks in one-criterion variance analysis. Journal of the American statistical Association, 24(5), 583-621. doi:10.3122/jabfm.2011.05.110213.

Lera-López, F. \& Rapún-Gárate, M. (2011). Determinants of sports participation and attendance: differences and similarities. International Journal of Sports Marketing and Sponsorship, 12(2), 66-89. doi:10.1108/IJSMS-12-02-2011B007.

Lesser, J.A. \& Hughes, M.A. (1986). The Generalizability of Psychographic Market Segments across Geographic Locations. Journal of Marketing, 50(1), 18. doi:10.2307/1251275.

Lilliefors, H.W. (1967). On the Kolmogorov-Smirnov test for normality with mean and variance unknown. Journal of the American Statistical Association, 62(318), 399-402. Retrieved from http://www.jstor.org/stable/2283970.

Liu, Y.-D., Taylor, P. \& Shibli, S. (2008). Utilizing importance data to identify customer segments for English public sport facilities. Managing Leisure, 13(3-4), 189-206. doi:10.1080/13606710802200886.

Luna-Arocas, R. \& Li-Ping Tang, T. (2005). The Use of Cluster Analysis to Segment Clients of a Sport Center in Spain. European Sport Management Quarterly, 5(4), 381-413. doi:10.1080/16184740500430256.

MacIntosh, E. \& Law, B. (2015). Should I stay or should I go? Exploring the decision to join, maintain, or cancel a fitness membership. Managing Sport and Leisure, 20(3), 191-210. doi:10.1080/23750472.2015.1025093.

Massey Jr, F.J. (1951). The Kolmogorov-Smirnov test for goodness of fit. Journal of the American Statistical Association, 68-78. Retrieved from http://www.jstor.org/stable/2280095.

Moreira, A. C., \& Silva, P. M. F. D. (2016). Complaint behaviour by third parties: exploring service quality, customer satisfaction and word-of-mouth in health clubs. International Journal of Sport Management and Marketing, 16(3-6), 152-171. doi: 10.1504/IJSMM.2016.077923.

Pedragosa, V. \& Correia, A. (2009). Expectations, satisfaction and loyalty in health and fitness clubs. International Journal of Sport Management and Marketing, 5(4), 450. doi:10.1504/IJSMM.2009.023371.

Pritchard, M.P., Nichols, T. \& Graber, N. (2016). Employee Health: Motivations and Constraints to Fitness Program Participation, 344-347. doi:10.1007/978-3-319-24184-5_90.

Resnick, B., Palmer, M.H., Jenkins, L.S. \& Spellbring, A.M. (2000). Path analysis of efficacy expectations and exercise behaviour in older adults. Journal of Advanced Nursing, 31(6), 1309-1315. doi:10.1046/j.1365-2648.2000.01463.x.

Robinson, L. (2006). Customer expectations of sport organisations. European Sport Management Quarterly, 6(1), 67-84. doi: $10.1080 / 16184740600799204$.

Robinson, L., Prichard, I., Nikolaidis, A., Drummond, C., Drummond, M., \& Tiggemann, M. (2017). Idealised media images: The effect of fitspiration imagery on body satisfaction and exercise behaviour. Body Image, 22, 6571.DOI: $10.1016 /$ j.bodyim.2017.06.001.

Rohm, A.J., Milne, G.R. \& McDonald, M.A. (2006) A Mixed-Method Approach for Developing Market Segmentation Typologies in the Sports Industry. Sport Marketing Quarterly, 15(1), 29-39.

Ryan, R.M., Frederick, C.M., Lepes, D., Rubio, N., et al. (1997) Intrinsic motivation and exercise adherence. International Journal of Sport Psychology, 28(4), 335-354. Retrieved from https://www.scopus.com/inward/record.uri?eid=2-

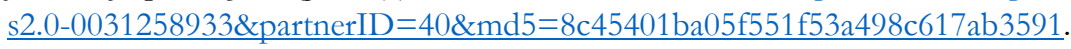

Salci, L. E., \& Ginis, K. A. M. (2017). Acute effects of exercise on women with pre-existing body image concerns: A test of potential mediators. Psychology of Sport and Exercise, 31, 113-122. doi:10.1016/j.psychsport.2017.04.001.

Schijns, J. M., Caniëls, M. C., Le Conté, J., \& Schijns, J. M. (2016). The Impact of Perceived Service Quality on Customer Loyalty in Sports Clubs. International Journal of Sport Management, Recreation and Tourism, 24, 42-75. doi: 10.5199/ijsmart-1791-874X-24c.

Sears, S.R. \& Stanton, A.L. (2001). Expectancy-value constructs and expectancy violation as predictors of exercise adherence in previously sedentary women. Health Psychology, 20(5), 326-333. doi:10.1037/0278-6133.20.5.326.

Seippel, Ø. (2006). The Meanings of Sport: Fun, Health, Beauty or Community? Sport in Society, 9(1), 51-70. doi:10.1080/17430430500355790.

Smith, W.R. (1956). Product Differentiation and Market Segmentation as Alternative Marketing Strategies. Journal of Marketing, 21(1), 3. doi:10.2307/1247695.

TNS Opinion \& Social (2014). Sport and physical activity. Special Eurobarometer 412. doi:10.2766/73002.

Wahlich, C., Beighton, C., Victor, C., Normansell, R., Cook, D., Kerry, S., ... \& Limb, E. (2017). 'You started something... then I continued by myself: a qualitative study of physical activity maintenance. Primary health care research \& development, 1-17. doi:10.1017/S1463423617000433. 
Ward, JH, J. (1963). Hierarchical grouping to optimize an objective function. Journal of the American Statistical Association. 58 (301), 236-244. Retrieved from http://www.tandfonline.com/doi/abs/10.1080/01621459.1963.10500845.

Wedel, M. \& Kamakura, W.A. (2012). Market Segmentation: Conceptual and Methodological Foundations. International Series in Quantitative Marketing. Springer US. Retrieved from https://books.google.pt/books?id=XxLaBwAAQBAJ.

Whaley, M.H., Brubaker, P.H., Otto, R.M. \& Armstrong, L.E. (2006). ACSM's guidelines for exercise testing and prescription. 7th edition. Lippincott Williams \& Wilkins.

Zopiatis, A., Theocharous, A. L., Constanti, P., \& Tjiapouras, L. (2017). Quality, Satisfaction and Customers' Future Intention: The Case of Hotels' Fitness Centers in Cyprus. Journal of Quality Assurance in Hospitality \& Tourism, 18(1), 1-24. doi:10.1080/1528008X.2015.1133366.

Zuzda, J.G., Esteves, D., Pinheiro, P.G., Rodrigues, R., et al. (2011) Gender Differences Expectations Towards Exercise Rehabilitation. Medicine \& Science in Sports \& Exercise, 43 (Suppl 1), 322-323. doi:10.1249/01.MSS.0000400888.45016.7a. 